\title{
MECANISMOS PARA O DESENVOLVIMENTO DO LETRAMENTO CRÍTICO (VISUAL) NO LIVRO DIDÁTICO DE INGLÊS
}

\author{
Daiane Aline Kummer ${ }^{1^{*}}$ \\ Graciela Rabuske Hendges ${ }^{1 * *}$ \\ ${ }^{1}$ Universidade Federal de Santa Maria, Santa Maria, RS, Brasil
}

\begin{abstract}
Resumo
Neste trabalho exploramos o conceito de letramento crítico (visual) por meio da análise de um livro didático de inglês do Programa Nacional do Livro Didático. Com base em um enquadramento analítico que combina os planos comunicativos da gramática sistêmico-funcional (HALLIDAY, 1994; HALLIDAY; MATTHIESSEN, 2014), os níveis analíticos da análise crítica do discurso (FAIRCLOUGH, 1992b; 2003) e o conceito de tipos de raciocínios e de práticas (ROJO, 2004; 2009; TRIVISIOL, 2017), analisamos 132 atividades de compreensão e de produção escrita. Elaboramos um contínuo de tipos de raciocínios e de práticas que vão desde a codificação ao letramento crítico e verificamos que um número significativo de atividades explora o letramento crítico $(51-38,6 \%)$. Avaliamos esse resultado positivamente, mas sugerimos que as atividades devem explorar uma variedade maior de raciocínios e de práticas de letramento crítico para chegar à formação da cidadania ativa.

Palavras-chave: Letramento Crítico; Letramento Crítico Visual; Livro Didático de Inglês; Ideologia; Tipos de Raciocínios e de Práticas.
\end{abstract}

\section{MECHANISMS FOR THE DEVELOPMENT OF (VISUAL) CRITICAL LITERACY IN ENGLISH LANGUAGE TEXTBOOKS}

\begin{abstract}
In this study we explore the concept of critical (visual) literacy through the analysis of an English as an additional language textbook approved by the Brazilian National Textbook Program (Programa Nacional do Livro
\end{abstract}

\footnotetext{
*Doutora em Letras pela Universidade Federal de Santa Maria. Professora da UFSM, no Departamento de Metodologia do Ensino. Interesses de pesquisa: Análise Crítica de Gênero, multiletramentos, letramento crítico, ensino de inglês, análise e produção de material didático, formação de professores. E-mail: daianekummer@ hotmail.com ORCID: https://orcid.org/0000-0003-1512-3380.

${ }^{* *}$ Doutora em Letras-Inglês (Universidade Federal de Santa Catarina). Professora da Universidade Federal de Santa Maria, no Departamento de Letras Estrangeiras Modernas e no Programa de Pós-Graduação em Letras. Membro do Laboratório de Pesquisa e Ensino de Leitura e Redação (LabLeR). Seus interesses de pesquisa incluem Análise Crítica de Gênero, multiletramentos e formação de professores. E-mail: gracielahendges@ hotmail.com. ORCID https://orcid.org/0000-0001-7326-0223.
} 
Didático). Based on an analytical framework that combines systemic functional grammar (HALLIDAY, 1994; HALLIDAY; MATTHIESSEN, 2014), critical discourse analysis (FAIRCLOUGH, 1992b, 2003) and the notion of types of reasoning and of practices (ROJO, 2004; 2009; TRIVISIOL, 2017), we analyzed 132 reading and writing activities. We elaborated a continuum of types of reasoning and of practices that range from decodification to critical literacy and found that a significant amount of activities in the textbook explore critical literacy (51-38,6\%). We evaluate this result positively, but suggest that the activities need to explore a wider range of reasonings and of practices to promote critical literacy for active citizenship.

Keywords: Critical Literacy; Visual Critical Literacy; English Language Textbook; Ideology; Types of Reasoning and of Practices. 


\section{Introdução}

O debate em prol de uma abordagem crítica para as pesquisas sobre a linguagem iniciou-se há pelo menos quatro décadas, na Grã-Bretanha, sob a denominação de linguística crítica (MAGALHÃES, 2005, p. 2). Ampliada e sistematizada em meados dos anos 1980 por Fairclough para se chamar "Análise Crítica do Discurso" (ou Análise do Discurso Crítica) (cf. MAGALHÃES, 2005, p. 2), a perspectiva crítica no estudo da linguagem tinha chegado para ficar, passando a exercer crescente influência sobre pesquisas em outras áreas da Linguística Aplicada. Nesse processo, passamos a observar a presença do termo "crítico/a" associado a áreas de pesquisa que originalmente não o usavam, tais como letramento crítico (CERVETTI; PARDALES; DAMICO, 2001), Análise Crítica de Gênero (MOTTA-ROTH, 2008a; MOTTA-ROTH; HEBERLE, 2015; BHATIA, 2008, 2015) e Análise Crítica do Discurso Multimodal (MACHIN, 2013; VAN LEEUWEN, 2013).

O letramento crítico (LC) também é apontado como objetivo escolar em políticas públicas brasileiras para a educação, tais como as Orientações Curriculares para o Ensino Médio (BRASIL, 2006) e o Programa Nacional do Livro Didático (BRASIL, 2013). Para Luke (2014, p. 21), tal perspectiva implica uma "orientação política ao ensino e a aprendizagem e ao conteúdo cultural, ideológico e sociolinguístico do currículo". Em termos de formação, o LC "é sobre capacitar os jovens a lerem ambos a palavra e o mundo em relação a poder, identidade, diferença e acesso a conhecimento, habilidades, ferramentas e recursos" (JANKS, 2013, p. 227).

O LC pode ser considerado o ápice de um conjunto de letramentos necessários para a participação na sociedade contemporânea, cada vez mais permeada por tecnologias, imagens e novos gêneros discursivos. A formação de leitores e produtores de textos aptos a lidar criticamente com essa diversidade de recursos semióticos (multimodalidade) e de contextos culturais (multiculturalidade) depende de uma pedagogia que preveja tais multiletramentos (CAZDEN et al., 1996; COPE; KALANTZIS, 2000). As múltiplas possibilidades de combinações de imagem, som, cor, gesto, textura e linguagem nos textos são delimitadas pelas convenções de cada contexto cultural, que por sua vez são moldados por condições sócio-históricas, étnicas, políticas, econômicas, institucionais. Ser multiletrado (criticamente) é essencial para lidar com "maneiras de trabalhar em novas ou transformadas formas de emprego, novas maneiras de participação como cidadão em espaços públicos, e mesmo talvez novas formas de identidade e personalidade" (COPE; KALANTZIS, 2009 p. 169).

Apesar do debate crescente sobre o LC na esfera pedagógica, operacionalizá-lo no ensino de língua inglesa propriamente dito parece não ser tarefa fácil (PREDEBON, 2015; KUMMER, 2015). Podemos pensar em diversos fatores interligados que levam a essa dificuldade, dentre eles a estrutura do ensino de línguas adicionais na escola (objetivo, carga-horária), a falta de investimento na formação continuada dos professores, a falta de um realinhamento nos papeis de professor e aluno e na sua relação com o que conta ou não como "conteúdo". É de 
se esperar que essas dificuldades sejam acentuadas quando se trata da leitura de imagens, principalmente porque o letramento visual é um aspecto relativamente novo na pesquisa sobre linguagem e, mais ainda, no ensino de linguagem, e as ações de formação de professores sobre o tema ainda são limitadas ou inacessíveis. Acreditamos que o livro didático pode ser um mecanismo para que essas perspectivas alcancem a sala de aula mais democraticamente.

Dessa forma, neste trabalho, analisamos em que medida e como o LC é mobilizado em atividades de um livro didático de inglês para o ensino fundamental, aprovado pelo Programa Nacional do Livro Didático para o triênio 2014-2016 (BRASIL, 2016). Nessa exploração, ressaltamos o LC voltado à leitura/produção de imagens, o qual denominamos letramento crítico visual (LCV). Nosso recorte está especificamente em contribuir na proposta de mecanismos que tornem o trabalho com o LC e com o LCV mais evidente, familiar e habitual.

\section{Letramento crítico e letramento crítico visual}

Uma perspectiva que tenha como base o LC reconhece a necessidade de desenvolver saberes de conscientização sobre as ideologias e relações de poder presentes nas interações sociais. Fairclough ([1989] 2001, p. 193) explica que a "consciência crítica da linguagem" possibilita uma tomada de consciência sobre as representações expressas nos textos. Essa conscientização permite, então, o empoderamento dos indivíduos frente às situações discursivas e sua transformação em "atores contra situações opressivas" (CERVETTI; PARDALES; DAMICO, 2001, p. 6).

Cervetti, Pardales e Damico (2001, p. 7) explicam que diferentes versões de LC compartilham o foco no caráter social e político do conceito de letramento, entendendo que auxiliar estudantes a se tornarem letrados criticamente envolve capacitá-los a entender como a ideologia molda as representações de realidades em textos.

Ao serem encorajados a tomar uma atitude crítica frente aos textos, os estudantes os reconhecem como construções sociais e históricas, permitindo o questionamento sobre visões de mundo ali instanciadas e a possibilidade de rejeitar e/ou reconstruir esses textos a partir de suas próprias experiências. Isso se dá a partir da possibilidade de problematização e de transformação/mudança social por meio desses textos (CERVETTI; PARDALES; DAMICO, 2001, p. 7). Nessa perspectiva, uma abordagem com foco no LC evidencia questões sobre poder e diferenças sociais relacionadas à "raça, classe, gênero, orientação sexual, e assim por diante", além de ver os estudantes não só como leitores críticos, mas também como atores capazes de transformar a sociedade (CERVETTI; PARDALES; DAMICO, 2001, p. 9).

Ao estudar a linguagem sob uma perspectiva crítica, partimos do pressuposto de que a linguagem "é parte irredutível da vida social" (FAIRCLOUGH, 2003, p. 2) e o seu uso nos posiciona como sujeitos particulares, com visões de mundo e ideologias específicas (FAIRCLOUGH, 1992a; b; 2003; JANKS, 2013). Nesse sentido, uma pesquisa desenvolvida sob um ponto de vista crítico tem o objetivo 
de "evidenciar como convenções e práticas de linguagem são investidas de relações de poder e processos ideológicos, os quais as pessoas frequentemente não percebem" (FAIRCLOUGH, 1992a, p. 7). Conceitos essenciais dessa perspectiva estão relacionados à visão de linguagem como prática social e à necessidade de consideração do contexto da linguagem em uso, em outras palavras, a existência de uma relação dialética entre um evento discursivo e as situações, instituições, e estruturas sociais.

Paulo Freire é um pesquisador brasileiro com destaque mundial dentre os estudiosos críticos (1989; 2011, além de outras publicações). Freire foi responsável por um estudo seminal sobre a necessidade de desenvolvimento de uma consciência crítica, e que serviu de base para o desenvolvimento de uma pedagogia crítica e também para o conceito de LC (CERVETTI; PARDALES; DAMICO, 2001; MOTTA-ROTH, 2008a; MOTTA-ROTH; HEBERLE, 2015; LANKSHEAR; KNOBEL, 2011), embora a nomenclatura "letramento crítico" não tenha sido usada pelo pesquisador.

Podemos dizer que, assim como na Análise Crítica do Discurso, a visão "crítica" implica o desenvolvimento de uma consciência sobre as visões de mundo e ideologias que permeiam a linguagem e sobre a possibilidade de mudança (FAIRCLOUGH, 1992b), os principais interesses de Freire também residiam no desenvolvimento de uma consciência crítica sobre o lugar de cada pessoa no mundo, prevendo a problematização e transformação de situações de desigualdade (CERVETTI; PARDALES; DAMICO, 2001).

Neste ponto cabe ressaltar que todas as postulações acima sobre o LC são generalizáveis para todos os recursos semióticos (imagem, cor, tipografia, layout, som, textura, espaço 3-D, etc.), não só para a linguagem verbal. Para diversos autores (KRESS, 1997; UNSWORTH, 2001; KRESS; JEWITT, 2003; KRESS; VAN LEEUWEN, 1996; 2006), a comunicação sempre foi multissemiótica, mas atualmente os recursos não-verbais têm ganhado uma saliência crescente em vários contextos, tradicionais e emergentes. Esses recursos são igualmente imbuídos de visões ideológicas e há uma urgência em desenvolvermos tecnologias para analisar como se materializam, pois relações de poder e ideologias opressoras tais como o racismo em imagens podem ser "muito mais facilmente negadas, muito mais facilmente classificadas como estando 'nos olhos de quem vể do que o racismo verbal" (VAN LEEUWEN, 2008, p. 137).

Para Jordão (2016, p. 42), no contexto escolar, ver o LC como uma missão do professor de "salvar" seus alunos não é produtivo porque pode levar "a uma imensa frustração e/ou à arrogância”. Uma abordagem viável prevê um professor que, dentro de seus limites e valendo-se dos conhecimentos trazidos pelos alunos, estimule-os a "problematizar as hierarquias sociais, questionar os sistemas de inclusão e exclusão, de valorização e desvalorização de pessoas e seus saberes", a construir "uma atitude reflexiva e aberta, receptiva à diversidade" (JORDÃO, 2016, p. 43-44).

A longo prazo, o ensino nessa perspectiva poderá contribuir para mobilidade e a justiça social, a qual tem como um passo essencial possibilitar acesso 
igualitário a como os textos funcionam (LUKE, 2014; JANKS, 2013). Nesse sentido, segundo Luke (2014, p. 27), um dos desafios do LC é equilibrar a relação entre conhecimentos sobre estruturas linguísticas dos textos e suas implicações discursivas e sociais, pois só é possível entender as funções hegemônicas e ideológicas dos textos munindo os estudantes com ferramentas - metalinguagem - para analisá-los.

Na próxima seção, exploramos duas abordagens que apresentam um ferramental para operacionalizar a relação entre texto e contexto: a linguística sistêmico-funcional e a análise crítica do discurso.

\section{Relações entre texto e contexto}

A perspectiva crítica na pesquisa e no ensino implica considerar a linguagem na sua densidade e complexidade, estabelecendo relações entre a camada mais visível/palpável e concreta do texto (do léxico e da gramática) e os níveis menos visíveis/palpáveis e abstratos do contexto (do discurso e da ideologia).

A sistematização desses níveis proposta pela Linguística Sistêmico-Funcional (HALLIDAY; HASAN, 1989; HALLIDAY, 1994; HALLIDAY; MATTHIESSEN, 2014) organiza a linguagem em seis planos comunicativos, do mais concreto ao mais abstrato: 1. fonologia e grafologia, 2. léxico-gramática, 3. semântica e pragmática, 4. registro no contexto de situação, 5. gênero no contexto de cultura e 6. ideologia, discurso. Ainda que por motivos analíticos seja viável separar a linguagem nesses níveis (ou "estratos"), ao usarmos a linguagem eles são inseparáveis: "acionamos - conscientemente ou não - todos esses níveis simultaneamente" (MEURER, 2011, p. 177) e os significados que produzimos resultam da fusão entre as camadas.

O mesmo princípio de estratificação em planos comunicativos pode ser estendido a outros recursos semióticos, tais como a imagem (KRESS; VAN LEEUWEN, 1996; 2006). O significado das imagens, assim como das palavras, é resultado da interação dos significados do plano superficial visível (tipo de traço usado - fino, espesso, irregular, reto, na presença ou não de cor, de linhas de direção - vetores, no tamanho dos volumes) com o plano menos palpável do discurso (relações de poder, visões de mundo, valores).

A complementaridade entre texto e contexto foi concebida por Fairclough (1992b) na forma de uma representação tridimensional, constituída de texto, prática discursiva e prática social, em que o texto é englobado pela prática discursiva que é compreendida pela prática social. Para o autor, a análise crítica do discurso envolve examinar as três dimensões: a) a análise do texto a partir da "descrição dos elementos linguísticos”, b) a análise da prática discursiva com a interpretação do texto considerando produção, distribuição e consumo; e c) a análise da prática social que pretende "explicar como o texto é investido de aspectos sociais ligados a formações ideológicas e formas de hegemonia" (MEURER, 2005, p. 94-95, grifo nosso). Fairclough (2003) sistematiza uma série de conceitos para a análise da ideologia nos textos, tais como intertextualidade, legitimação, agência, ação estratégica vs. ação comunicativa, equivalência e diferença, colocação, exclusão, conversacionalização da linguagem pública, cuja identificação é viabilizada pela 
análise de padrões lexicogramaticais dos textos, por meio da Gramática Sistêmico-Funcional (HALLIDAY, 1994; HALLIDAY; MATTHIESSEN, 2014).

A Figura 1 apresenta uma síntese das categorias analíticas específicas de cada plano comunicativo da linguagem, a partir da gramática sistêmico-funcional (HALLIDAY, 1994; HALLIDAY; MATTHIESSEN, 2014), da gramática visual (KRESS; VAN LEEUWEN, 1996; 2006), da análise crítica do discurso (principalmente FAIRCLOUGH, 2003, mas também categorias de VAN LEEUWEN, 1996; 2008, sobre representação de atores sociais) e das teorias de análise (crítica) de gênero (ASKEHAVE; SWALES, 2001; MOTTA-ROTH, 2008a; MOTTA-ROTH; HEBERLE, 2015).

Figura 1: Estratificação dos planos comunicativos e categorias de análise de recursos semióticos verbais e recursos semióticos imagéticos

\begin{tabular}{|c|c|c|c|c|c|}
\hline $\begin{array}{l}\text { Planos } \\
\text { comunicativos }\end{array}$ & \multicolumn{3}{|c|}{$\begin{array}{l}\text { Categorias de análise: recursos semióticos verbais } \\
\text { escritos }\end{array}$} & \multicolumn{2}{|c|}{$\begin{array}{l}\text { Categorias de análise de recursos semióticos } \\
\text { imagéticos estáticos }\end{array}$} \\
\hline Ideologia/Discurso & \multicolumn{3}{|c|}{$\begin{array}{l}\text { tipo de discurso (publicitário? estético? etc.) } \\
\text { legitimação } \\
\text { agência } \\
\text { representação de atores sociais } \\
\text { intertextualidade } \\
\text { universal e particular (hegemonia) } \\
\text { ação estratégica vs. ação comunicativa } \\
\text { cultura promocional } \\
\text { informalização de identidades públicas/ conversacionali- } \\
\text { zação da linguagem pública } \\
\text { equivalência e diferença, colocação }\end{array}$} & \multicolumn{2}{|c|}{$\begin{array}{l}\text { tipo de discurso (publicitário? estético? etc.) } \\
\text { legitimação } \\
\text { agência } \\
\text { representação visual de atores sociais } \\
\text { intertextualidade } \\
\text { universal e particular (hegemonia) } \\
\text { ação estratégica vs. ação comunicativa } \\
\text { cultura promocional } \\
\text { informalização de identidades públicas/ conversacionali- } \\
\text { zação da linguagem pública } \\
\text { equivalência e diferença, colocação }\end{array}$} \\
\hline $\begin{array}{l}\text { Contexto de } \\
\text { cultura: gênero }\end{array}$ & \multicolumn{3}{|c|}{$\begin{array}{l}\text { Propósito Comunicativo } \\
\text { Comunidade discursiva } \\
\text { Sistema e Conjuntos de gêneros } \\
\text { Organização retórica }\end{array}$} & \multicolumn{2}{|c|}{$\begin{array}{l}\text { Propósito Comunicativo } \\
\text { Comunidade discursiva } \\
\text { Sistema e Conjuntos de gêneros } \\
\text { Organização retórica }\end{array}$} \\
\hline $\begin{array}{l}\text { Contexto de } \\
\text { situação: registro }\end{array}$ & \multicolumn{3}{|l|}{$\begin{array}{l}\text { Campo } \\
\text { Relação } \\
\text { Modo }\end{array}$} & \multicolumn{2}{|c|}{$\begin{array}{l}\text { Campo } \\
\text { Relação } \\
\text { Modo }\end{array}$} \\
\hline $\begin{array}{l}\text { Semântica e } \\
\text { pragmática }\end{array}$ & \multicolumn{3}{|c|}{$\begin{array}{l}\text { Significados ideacionais } \\
\text { Significados interpessoais } \\
\text { Significados textuais }\end{array}$} & \multicolumn{2}{|c|}{$\begin{array}{l}\text { Significados representacionais } \\
\text { Significados interativos } \\
\text { Significados composicionais }\end{array}$} \\
\hline \multirow{5}{*}{ Léxico-gramática } & \multirow[t]{2}{*}{ Ideacional } & Transitividade & $\begin{array}{l}\text { Processos } \\
\text { Participantes } \\
\text { Circunstâncias }\end{array}$ & \multirow[t]{2}{*}{ Representacional } & \multirow{2}{*}{$\begin{array}{l}\text { Processos } \\
\text { Participantes } \\
\text { Circunstâncias } \\
\text { Parataxe/Hipotaxe }\end{array}$} \\
\hline & & Lógica & $\begin{array}{l}\text { Parataxe } \\
\text { Hipotaxe }\end{array}$ & & \\
\hline & \multirow{2}{*}{ Interpessoal } & Modo & $\begin{array}{l}\text { Proposições } \\
\text { Propostas }\end{array}$ & \multirow{2}{*}{ Interativa } & \multirow{2}{*}{$\begin{array}{l}\text { Contato } \\
\text { Distância social } \\
\text { Atitude } \\
\text { Poder } \\
\text { Modalidade }\end{array}$} \\
\hline & & Modalidade & $\begin{array}{l}\text { Modalização } \\
\text { Modulação }\end{array}$ & & \\
\hline & Textual & \multicolumn{2}{|c|}{$\begin{array}{l}\text { Tema-Rema } \\
\text { Tema Ideacional } \\
\text { Tema Interpessoal } \\
\text { Tema textual }\end{array}$} & Composicional & $\begin{array}{l}\text { Valores informacionais } \\
\text { Molduragem } \\
\text { Saliência }\end{array}$ \\
\hline $\begin{array}{l}\text { Grafologia/ } \\
\text { Fonologia/ } \\
\text { Gráfico }\end{array}$ & \multicolumn{3}{|c|}{$\begin{array}{l}\text { Sistema de sons e de escrita (fonemas, letras, sílabas, } \\
\text { palavras) }\end{array}$} & \multicolumn{2}{|c|}{ Sistema de imagem (vetor, linha, pixels) } \\
\hline
\end{tabular}

Fonte: Adaptado de Kummer (2015) e Florek (2015). 
A partir dessas perspectivas, reconhece-se a interconexão entre os diferentes níveis no uso da linguagem, entendendo que escolhas linguísticas (de vocabulário, de gramática, do sentido que pretendemos de determinada palavra ou expressão) influenciam/são influenciadas por questões de natureza social e discursiva (a identidade étnica e social e os papéis dos participantes na interação, os objetivos do gênero discursivo, os processos históricos, políticos, sociais que embasam valores e ideologias das instituições). Os LC e LCV pressupõem o reconhecimento dessa interconexão, o que não é uma tarefa fácil, porque demanda um profundo conhecimento dos contextos e dos textos.

Do ponto de vista da pesquisa em Linguística Aplicada, uma questão muito debatida, mas cada vez menos controversa, está relacionada aos procedimentos investigativos necessários para uma perspectiva crítica na pesquisa sobre linguagem. Um número crescente de pesquisadores tem argumentado pelo uso da etnografia como etapa crucial para alcançarmos as dimensões b e c da proposta metodológica de Fairclough (1992b) mencionada acima. Para interpretarmos as condições de produção, distribuição e consumo de um texto (dimensão b) e explicarmos ideologias, relações de poder, formas de hegemonia perpetuadas ou desafiadas nesse texto (dimensão c), é preciso um engajamento com o grupo social que usa o texto, observar suas rotinas, objetivos, metas, entrevistar membros do grupo para mapear suas representações, compreender suas visões, valores, motivações, histórias. A pesquisa crítica envolve um processo recursivo de coleta e análise de dados, em que o pesquisador retorna ao texto e ao contexto investigado várias vezes, em um movimento de zigue-zague, para revisar análises anteriores com base em novas informações e/ou coletar mais dados com base em análises, observações e/ou entrevistas prévias (ASKEHAVE; SWALES, 2001; BHATIA, 2004; MOTTA-ROTH, 2006; 2008a). Nessa abordagem, a postura, a atitude do pesquisador é inseparável da abordagem de pesquisa, ambas críticas porque demonstram consciência sobre a influência do contexto, da identidade, das vivências sobre as escolhas linguísticas e interpretações do mundo.

Uma proposta de ensino de linguagem sob uma perspectiva crítica também implica não perder de vista a dimensão discursiva ideológica da linguagem. Essa dimensão possibilita o reconhecimento de relações de poder, preconceitos expressos pela linguagem, e, em contraponto, assegura a possibilidade de desafiar tais relações e preconceitos, por meio do uso consciente e informado da linguagem (MOTTA-ROTH; HEBERLE, 2015). Nesse sentido, a Figura 1 indica que textos são mais do que vocabulário e gramática que, por isso, o conteúdo da aula de língua inglesa deve ir além desse nível para chegar ao questionamento dos diferentes efeitos de sentido que a escolha por uma ou outra palavra ou uma ou outra estrutura sintática podem ocasionar. Entretanto, conforme apontado na introdução deste trabalho, parece haver uma dificuldade de recontextualizar os conceitos e características do LC da literatura acadêmica para o contexto pedagógico. Elaborar atividades que explorem os níveis mais abstratos da linguagem e que podem levar ao LC, ou à "profundidade" do LC que se espera alcançar no ensino, pode significar um desafio na prática da sala aula. Em vista disso, na 
próxima seção, discutimos o que chamamos de "níveis de raciocínio e de prática" mobilizados no processo pedagógico e quais podem ser associados mais diretamente com o desenvolvimento de LC e LCV.

\section{Níveis de raciocínio e de prática para o desenvolvimento de LC}

Os níveis de raciocínio e de prática são concebidos aqui como processos cognitivos e atividades práticas demandados dos alunos para a resolução de tarefas escolares. Sugerimos os termos "raciocínio" e "prática" para fazer referência a tarefas, respectivamente, de caráter mental, interno (como "estabelecer relações funcionais e conexões lógicas") e de caráter material, externo ("localizar e/ou copiar informações" - dependendo da atividade de compreensão/produção escrita).

Chamados de "capacidades de leitura e de escrita" por Rojo (2004; 2009), esses níveis vão desde processos de repetição e memorização (capacidades referentes à alfabetização) até processos mais sofisticados como a interpretação, o estabelecimento de conexões entre o texto e seu contexto de situação e de conexões com outros textos, o reconhecimento de visões de mundo expressas no texto (ROJO, 2004). Como explica Rojo (2004, p. 4), "diferentes tipos de letramento, diferentes práticas de leitura, em diversas situações, vão exigir diferentes combinações de capacidades de várias ordens", dentre as quais a autora destaca três tipos: capacidades de decodificação, capacidades de compreensão e capacidades de interpretação e de interação. Trivisiol (2017) retoma o trabalho de Rojo (2004) e classifica as capacidades em a) capacidades de decodificação, b) capacidades de processamento cognitivo (capacidades de compreensão no trabalho de Rojo, 2004) e c) capacidades de leitura crítica (as capacidades de interpretação e interação de Rojo, 2004).

Os estudos de Cope e Kalantzis (2000), Kalantzis e Cope (2012) e Kalantzis et al. (2016) sobre a pedagogia dos multiletramentos também se concentram na sistematização de tipos de raciocínios, ou "processos de conhecimento" (knowledge processes), a serem desenvolvidos na escola para que os alunos tenham consciência sobre a) as convenções entre os diferentes modos semióticos combinados nos gêneros, ou seja, a multimodalidade e b) a diversidade social, cultural e linguística na sua escola, comunidade, país e no mundo, e de que forma essa diversidade influencia a maneira como nos comunicamos (KALANTZIS; COPE, 2012, p. 5).

Quatro processos de conhecimento são delineados na pedagogia de multiletramentos: experienciar, conceituar, analisar e aplicar (COPE; KALANTZIS, 2009; KALANTZIS; COPE, 2012; KALANTZIS et al., 2016). Experienciar está relacionado a explorar conceitos, ideias, textos familiares aos estudantes e investigar conceitos, ideias e textos novos aos estudantes; conceituar compreende processos de classificar, definir conceitos por nomeação, com categorias, termos e identificar, concluir, conectando conceitos e desenvolvendo teorias; analisar está relacionado a analisar o texto funcionalmente, por exemplo, com base em conexões lógicas de causa e efeito, e analisar o texto criticamente, quando os es- 
tudantes avaliam suas visões e interesses assim como de outras pessoas na produção de um texto; aplicar se refere a aplicar adequadamente, colocar em prática o conhecimento aprendido e praticado de forma inovadora, em um novo contexto, aplicando-o criativamente (KALANTZIS et al., 2016, p. 75). Entendendo pedagogia como um processo consciente e cuidadoso de selecionar e combinar processos de conhecimento conforme os objetivos de aprendizagem pretendidos, o professor poderia escolher a sequência mais adequada para cada contexto de ensino (KALANTZIS; COPE, 2012, p. 360).

Com base nos princípios e conceitos discutidos até aqui, elaboramos uma listagem de raciocínios e práticas e as organizamos na forma de um contínuo (Figura 2) considerando graus de complexidade entre as tarefas listadas (principalmente com base em TRIVISIOL, 2017, p. 77). Na nossa proposta, a cor mais escura representa raciocínios e práticas menos complexos a partir de elementos mais concretos do texto, variando para um tom intermediário até chegar ao mais claro, fazendo referência a raciocínios e práticas mais complexos, com base em aspectos mais abstratos do contexto, mais nebulosos à primeira vista. Da mesma forma, o uso de linhas pontilhadas entre os tipos de raciocínios e de práticas busca sugerir uma interdependência entre eles, no sentido de que alguns raciocínios e práticas podem funcionar como andaimes para o desenvolvimento de outros. 
Figura 2: Contínuo de tipos de raciocínios e de práticas em relação ao letramento crítico

Ação

- Aplicar o conhecimento de forma inovadora

- Problematizar significados/representações expressos nos textos ou situações, considerando outras representações/visões de mundo possíveis

- Debater respeitosamente pontos de vista conflitantes com o seu

- Intertextualizar (produção), levando em conta outros textos e discursos sobre os mesmos temas, para com eles concordar, discordar, dialogar

Letramento crítico

Reflexão

- Elaborar apreciações relativas a valores éticos e/ou políticos

- Comunicar, adequando o texto à situação de produção, a seus interlocutores-leitores, a seu suporte e veículo, de maneira a atingir suas finalidades

- Recuperar contexto do texto

- Elaborar apreciações estéticas e/ou afetivas

- Expressar suas opiniões pessoais

- Perceber relações de interdiscursividade

Identificação

- Perceber relações de intertextualidade

- Relacionar texto e contexto pessoal

- Definir finalidades e metas da atividade de leitura e/ou escrita

- Ativar conhecimentos de mundo

- Produzir inferências globais

- Engajar em textos (orais, escritos, visuais, etc.) não-familiares

- Explorar/pesquisar tópicos não-familiares

- Discutir sobre tópicos, pessoas e lugares familiares

- Produzir inferências locais

- Antecipar ou prever conteúdos ou propriedades dos textos

- Textualizar, organizando as informações e temas do texto de maneira progressiva e atribuindo-lhes coerência e coesão

Processamento cognitivo

- Organizar conhecimentos em esquemas

- Deduzir conclusões

- Estabelecer relações funcionais e conexões lógicas

- Fazer sentido de informações novas a partir de padrões prontos

- Distinguir similaridades e diferenças, classificar propriedades gerais e comuns

- Categorizar e nomear elementos que constituem um determinado conceito

- Comparar informações

- Generalizar

- Checar hipóteses

- Localizar e/ou copiar informações

- Normalizar o texto, em termos de ortografia, separação das palavras e pontuação adequadas, concordância verbal e nominal, regência verbal

- Ampliar a percepção para maiores proporções de texto

- Ler e reconhecer globalmente as palavras

- Decodificar palavras e textos escritos

- Dominar as relações entre grafemas e fonemas

- Compreender a natureza alfabética do nosso sistema de escrita

- Reconhecer o alfabeto

- Dominar as convenções gráficas

- Compreender diferenças entre escrita e outras formas gráficas

Fonte: Autoras, com base em Cervetti, Pardales e Damico (2001); Rojo (2004; 2009), Trivisiol (2017), Kalantzis et al. (2016). 
As tarefas menos complexas podem ser o reconhecimento das palavras e da pontuação (decodificação), passando pela localização de informações no nível superficial do texto (processamento cognitivo mais básico), pela identificação de relações lógicas entre partes do texto (processamento cognitivo intermediário), inferir o conteúdo do texto a partir do co-texto (processamento cognitivo mais avançado), até chegar a processos mais sofisticados atrelados a níveis mais abstratos da comunicação, como o gênero discursivo (convenções comunicativas culturais) e o discurso (representações sobre crenças e valores). Nesse contínuo, o letramento crítico é classificado como um conjunto de raciocínios e de práticas que vão desde a identificação (de pistas do contexto no texto, por exemplo), passando pela reflexão (por meio da problematização de visões de mundo naturalizadas, por exemplo), até a ação (ligada à agentividade do aluno, à cidadania ativa por meio da aplicação e intervenção no contexto do aluno). Assim, uma atividade que envolvesse raciocínios e práticas dessas três ordens completaria o "ciclo" de LC, dado que não basta identificar e refletir sobre situações de desigualdade, conforme autores como Freire (1989; 2011), Fairclough (1992b), Cervetti, Pardales e Damico (2001), Motta-Roth (2008b), Luke (2014), é preciso pensar em mudanças/transformações dessas situações.

É preciso destacar que a exploração dessas capacidades não necessariamente segue uma ordem fixa. Em uma mesma atividade, elas podem variar de um extremo a outro, como os resultados de Trivisiol (2017) demonstram, equilibrando raciocínios mais concretos ou mais abstratos, pois dependem do objetivo da aula, das possibilidades de professores e alunos, do contexto de ensino.

\section{Metodologia}

Para a realização deste estudo, consideramos como universo de análise o Programa Nacional do Livro Didático (PNLD) no triênio 2014-2016 (BRASIL, 2016) associado ao contexto de ensino fundamental de inglês de escolas públicas de Santa Maria, no interior do estado do Rio Grande do Sul. ${ }^{1}$ O PNLD, programa do Fundo Nacional de Desenvolvimento da Educação (FNDE), é responsável pela "distribuição de coleções de livros didáticos aos alunos da educação básica" (BRASIL, 2016). Essa distribuição é gratuita para as escolas públicas e facilita o acesso de alunos e professores a livros didáticos de diversas áreas.

Dentre as três coleções de livros didáticos aprovadas pelo PNLD 2014-2016 para os anos finais do ensino fundamental, selecionamos a Vontade de saber Inglês (KILLNER; AMANCIO, 2012) por ser predominante dentre as 74 escolas estaduais e municipais de Santa Maria com anos finais do ensino fundamental e cadastradas no PNLD (Figura 3). Na rede estadual, 16 (53\%) de 30 escolas adotam a Vontade de saber Inglês e na rede municipal, $21\left(48 \%^{2}\right)$ de 44 escolas. 
Figura 3: Distribuição dos livros didáticos de ensino fundamental nas escolas estaduais e municipais de Santa Maria.

a. Escolas estaduais

LDs - Ensino Fundamental (anos finais)

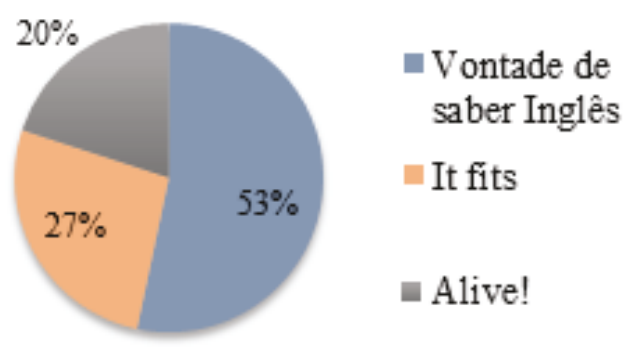

b. Escolas municipais

\section{LDs - Ensino Fundamental (anos finais)}

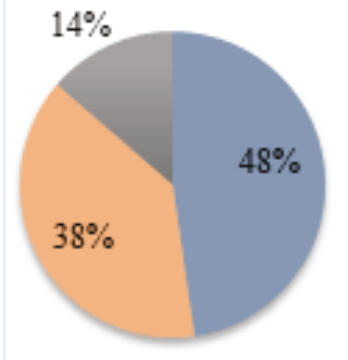

Vontade de saber

Inglês

It fits

alive!

Fonte: Kummer (2019), com base em BRASIL (2014).

\section{O corpus}

A coleção Vontade de saber inglês (KILLNER; AMANCIO, 2012) reúne quatro volumes, um para cada ano dos anos finais do ensino fundamental $\left(6^{\circ}, 7^{\circ}\right.$, $8^{\circ}$ e $9^{\circ}$ anos). Selecionamos para análise o Volume 4, indicado para o $9^{\circ}$ ano do ensino fundamental. Partimos do pressuposto de que conhecimentos de natureza crítica são enfocados de forma mais consistente nos anos finais de cada ciclo de ensino, por exigirem significativo conhecimento da estrutura linguística, serem mais complexos e abstratos. Tal suposição é também reconhecida por Tílio (2012, p. 1007) que sugere que o "amadurecimento" dos estudantes possa facilitar um trabalho fundamentado em uma perspectiva crítica. Contudo, concordamos com o autor que explica que isso não significa que "não possa ser iniciado mais cedo; muito pelo contrário: acredito que tais práticas de letramento deveriam estar presentes desde o início da formação leitora do aprendiz" (TÍLIO, 2012, p. 1007). ${ }^{3}$

O livro analisado é um exemplar do Manual do Professor, que apresenta organização igual ao Livro do Aluno, mas com a adição de sugestões de respostas para as atividades, sugestões para o professor no decorrer das unidades e uma seção de "Orientações para o professor" no final dos livros.

Em termos de organização, o livro selecionado inclui oito unidades divididas em seções direcionadas para o desenvolvimento de habilidades de leitura ("Reading moment 1", "Reading moment 2"), de vocabulário ("The World of Words"), de gramática ("Think about it"), de produção escrita ("Writing moment"), de compreensão oral ("Listening Moment"), de produção oral ("Conversation Moment"), e uma seção de autoavaliação ("Reflecting on the unit"), que apresenta a reflexão sobre o que o aluno aprendeu na unidade.

Dentre as diferentes seções, examinamos as atividades das seções de compreensão escrita (apenas a primeira de cada unidade: "Reading moment 1") e das seções de produção escrita, em cada uma das oitos unidades do livro, totalizando 16 seções e 132 atividades (Tabela 1 ). 
Tabela 1: Número de atividades por unidade

\begin{tabular}{|l|l|l|l|l|l|l|l|l|l|}
\hline Seções & Unit $\mathbf{1}$ & Unit 2 & Unit 3 & Unit 4 & Unit 5 & Unit 6 & Unit 7 & Unit 8 & TOTAL \\
\hline Reading moment 1 & 12 & 11 & 11 & 14 & 11 & 16 & 13 & 8 & 96 \\
\hline Writing moment & 3 & 4 & 5 & 3 & 4 & 7 & 5 & 5 & 36 \\
\hline TOTAL & 15 & 15 & 16 & 17 & 15 & 23 & 18 & 13 & 132 \\
\hline
\end{tabular}

Fonte: Autoras.

A escolha das seções de compreensão escrita está relacionada à característica dessas seções de apresentar um texto e questões sobre ele, normalmente uma das maiores seções dos livros (com um número maior de atividades, conforme observado em uma análise assistemática do livro). Ademais, o livro inclui duas seções de compreensão escrita em cada unidade, demonstrando a importância dada a tal seção e/ou aos conhecimentos relacionados a ela. Selecionamos as seções de produção escrita por entendermos sua relevância na perspectiva do letramento crítico, como uma seção que possibilita ampliação de repertório de práticas do aluno e exercício de posturas de problematização, tolerância respeitosa à diversidade, negociação de conflito.

\section{Procedimentos e categorias de análise}

A análise das 132 atividades seguiu os seguintes passos:

1. Discriminação dos enunciados das atividades a serem analisados: muitas atividades incluem um enunciado principal (p. ex. "1. Before you read, answer these questions") e, na sequência, enunciados que demandam tarefas específicas de leitura ou escrita. Para a análise, contabilizamos os enunciados que demandam a resolução de tarefas específicas. Em alguns casos, apenas um enunciado é suficiente para solicitar uma tarefa enquanto que, em outros casos, cada enunciado secundário demanda tarefas distintas, sendo contabilizados separadamente. Também foram contabilizadas atividades extras presentes nas orientações ao professor, tanto no decorrer das seções analisadas como nas orientações ao professor no capítulo final do livro;

2. Identificação de atividades que mobilizam LC: nessa etapa, realizamos um mapeamento indutivo de pistas linguísticas, definidas a partir de repetidas leituras do corpus e reconhecimento de termos salientes. A saliência pode ser definida por uso repetido e padronizado e pela relevância contextual de um elemento linguístico, que passa a ser um elemento rico em significação (BARTON, 2004, p. 66). No caso desta pesquisa, elementos ricos em significação são aqueles que se referem a palavras que podem ser tipicamente relacionadas ao elemento crítico, como: "crítico", "reflexão", "opinião", "inclusão/exclusão", "desigualdade", "mudança", "diferente", ou ainda processos como "pensar", "refletir", "problematizar", "questionar", "opinar”. Nesta pesquisa damos destaque a esses elementos quando estão associados a saberes do nível da Ideologia (na estratificação da LSF), ou seja, à necessidade de re- 
conhecer visões de mundo, relações de poder, preconceito e discriminação, de identificar a representação de atores sociais como incluídos ou excluídos da representação, por exemplo; agência, relações intertextuais e interdiscursivas, além da necessidade de identificar representações construídas como naturalizadas, por exemplo;

3. verificação quantitativa: nesta etapa, contabilizamos o número de atividades que fazem referência aos saberes de LC e classificamos os níveis de raciocínio e de prática (conforme Figura 2) mobilizados com mais e menos frequência;

4. identificação de atividades que mobilizam LCV: dentre as atividades identificadas no passo 2, nesta etapa concentramos a atenção apenas àquelas que exploram o letramento crítico com base em recursos semióticos imagéticos estáticos. Para tanto, partimos de pistas nos enunciados a) que continham os termos "imagem", "figura", "quadro", "esquema", b) que faziam referência implícita às imagens por meio do termo "texto", uma vez que esse termo engloba os diferentes recursos semióticos que constituem um texto, e c) que nomeavam um gênero essencialmente multimodal como "história em quadrinho", "mapa", "notícia" e outros que também incluem diferentes recursos semióticos.

As análises foram realizadas tendo como pano de fundo o contexto político educacional no qual o livro didático foi produzido, considerando o edital que regulou a edição do PNLD da coleção da qual o livro analisado faz parte (BRASIL, 2011) e, mais detalhadamente, a resenha do Guia de livros didáticos da coleção selecionada (BRASIL, 2013), bem como os Parâmetros Curriculares Nacionais (BRASIL, 1998) e as Orientações Curriculares para o Ensino Médio (BRASIL, 2006).

\section{Resultados}

Identificamos 51 (38,6\%) atividades de LC e dentre estas, 5 (9,8\%) de LCV (Tabela 2). Detalhamos e discutimos esses resultados separadamente nas subseções que seguem.

Tabela 2: Atividades das seções que demandam saberes de LC e LCV

\begin{tabular}{|c|c|c|c|c|c|}
\hline \multirow[t]{2}{*}{ Seções } & \multirow[t]{2}{*}{$\begin{array}{l}\text { Total de } \\
\text { atividades das } \\
\text { seções }\end{array}$} & \multicolumn{2}{|c|}{$\begin{array}{l}\text { Atividades que mobilizam } \\
\text { LC }\end{array}$} & \multicolumn{2}{|c|}{$\begin{array}{l}\text { Atividades que mobilizam } \\
\text { LCV (dentre as atividades } \\
\text { de LC) }\end{array}$} \\
\hline & & $n$ & $\%$ & $\mathrm{n}$ & $\%$ \\
\hline $\begin{array}{l}\text { Compreensão } \\
\text { escrita }\end{array}$ & 96 & 33 & 34,4 & 3 & 9,1 \\
\hline Produção escrita & 36 & 18 & 50 & 2 & 11,1 \\
\hline Total & 132 & 51 & 38,6 & 5 & 9,8 \\
\hline
\end{tabular}

Fonte: Autoras. 


\section{As atividades de LC}

Entendemos que 38,6\% (51 atividades) de atividades que promovem LC é um percentual significativo a ser celebrado, pois pode indicar uma aproximação entre ciência linguística e contexto pedagógico, um diálogo coeso com base em conceitos e princípios que podem levar a ganhos significativos de aprendizagem. Discutiremos primeiramente as atividades com foco no nível da ideologia e, depois, a classificação e quantificação das atividades com relação aos tipos de raciocínios e de práticas que acionam.

Nossa proposta de classificação das atividades do nível da ideologia está baseada nos fundamentados na análise crítica do discurso (FAIRCLOUGH, 2003; VAN LEEUWEN, 1996; 2008), ou seja, em atividades que exploram questões ligadas a como os textos expressam visões de mundo, legitimam comportamentos; representam atores sociais (excluem, incluem, discriminam), revelam intertextualidade, são "contaminados" pela cultura promocional, usam recursos de informalização/conversacionalização na esfera pública como estratégias de mitigação de relações de poder e autoridade (conforme delineado na Figura 1). Ressaltamos que uma mesma atividade pode mobilizar mais de um nível da linguagem (gênero, registro, por exemplo), além da ideologia, os quais não abordamos explicitamente neste trabalho. Além disso, cada atividade pode demandar saberes sobre mais de uma categoria da ideologia, como de atores sociais e de identidade, por isso, nas 51 atividades que promovem LC (Tabela 2), encontramos 93 ocorrências de exploração do nível da ideologia (Tabela 3), com significativa ênfase em "visões de mundo, pontos de vista" (84,3\% de 51 atividades), tanto nas 33 atividades de compreensão escrita (27 - 81,8\%), quanto nas 18 atividades de produção escrita $(16-88,8 \%)$.

Tabela 3: Aspectos do nível da ideologia abordados nas atividades

\begin{tabular}{l|l|l|l}
\hline Compreensão escrita & \multicolumn{1}{l}{ Aspectos da ideologia } & \multicolumn{1}{l}{ Produção escrita } & \multicolumn{1}{l}{ Total } \\
\hline $27(81,8 \%)$ & visões de mundo, pontos de vista & $16(88,8 \%)$ & $43(84,3 \%)$ \\
\hline $12(36,3 \%)$ & identidade & $6(33,3 \%)$ & $18(35,2 \%)$ \\
\hline $10(30,3 \%)$ & valores éticos & $5(27,7 \%)$ & $15(29,4 \%)$ \\
\hline $5(15,1 \%)$ & naturalizações & 0 & $5(9,8 \%)$ \\
\hline $1(3,03 \%)$ & intertextualidade, interdiscursividade & $3(16,6 \%)$ & $4(7,8 \%)$ \\
\hline $3(9,1 \%)$ & agência & $1(5,5 \%)$ & $4(7,8 \%)$ \\
\hline $3(9,1 \%)$ & representação de atores sociais & 0 & $3(5,9 \%)$ \\
\hline 0 & relações de poder & $1(5,5 \%)$ & $1(1,9 \%)$ \\
\hline 61 ocorrências em & & 32 ocorrências em & 93 ocorrências em 51 \\
33 atividades $(\mathbf{1 0 0} \%)$ & & $\mathbf{1 8}$ atividades $(\mathbf{1 0 0} \%)$ & atividades $(\mathbf{1 0 0 \% )}$ \\
\hline
\end{tabular}

Fonte: Autoras.

Além da ênfase em "visões de mundo, pontos de vista", a ocorrência dos aspectos "identidade" e "valores éticos" pode ser associada à possibilidade de essas categorias facilitarem a inclusão das experiências dos estudantes na aula, pois 
em sua grande maioria a discussão dos enunciados sobre esses três aspectos são sobre os alunos ("Em/Qual sua opinião", "O que você pensa sobre..., "Você concorda com...") e com menos frequência sobre identificar e problematizar as representações expressas nos textos. Essa tendência é corroborada quando exploramos os tipos de raciocínios e de práticas de LC explorados em cada atividade.

Classificamos 115 ocorrências dos raciocínios e práticas de LC nas atividades, dos quais 72 (62,6\%) são de Reflexão (Tabela 4). Dentre os tipos de Reflexão (total), predominam atividades de "expressar opiniões pessoais" (34-66,7\%). Em segundo lugar, estão os raciocínios e práticas de Identificação, presentes em 41 atividades (35,6\%), com predomínio de atividades de "relacionar texto e contexto pessoal" (25 - 49\%). Entretanto, quando consideramos as seções de compreensão escrita e de produção escrita separadamente, esses padrões são válidos apenas para as seções de compreensão escrita. Nas seções de produção escrita, os raciocínios e práticas de Reflexão predominantes são de "recuperar contexto do texto" $(61,1 \%)$ e os de Identificação são "definir finalidades e metas da atividade de leitura e/ou escrita $(72,2 \%)$.

Tabela 4: Raciocínios e práticas de LC abordados nas atividades

\begin{tabular}{|c|c|c|c|c|c|}
\hline \multicolumn{2}{|c|}{ Compreensão escrita } & \multirow{3}{*}{$\begin{array}{l}\text { Tipos de raciocínios e de práticas de letramento crítico } \\
\text { Engajar em ações sociais } \\
\text { Aplicar o conhecimento de forma inovadora }\end{array}$} & \multicolumn{2}{|c|}{ Produção escrita } & \multirow{3}{*}{$\begin{array}{l}\text { Total } \\
0 \\
2 \\
3,9 \%\end{array}$} \\
\hline \multirow{2}{*}{$\begin{array}{l}\text { Ação } \\
1 \\
(1,6 \%)\end{array}$} & 0 & & 0 & \multirow{2}{*}{$\begin{array}{l}\text { Ação } \\
1 \\
(1,8 \%)\end{array}$} & \\
\hline & $\begin{array}{l}1 \\
3,03 \%\end{array}$ & & $\begin{array}{l}1 \\
5,5 \%\end{array}$ & & \\
\hline \multirow{7}{*}{$\begin{array}{l}\text { Reflexão } \\
36 \\
(58,3 \%)\end{array}$} & $\begin{array}{l}4 \\
12,2 \%\end{array}$ & $\begin{array}{l}\text { Problematizar significados/representações expressos nos } \\
\text { textos ou situações, considerando outras representações/ } \\
\text { visões de mundo possíveis }\end{array}$ & $\begin{array}{l}4 \\
22,2 \%\end{array}$ & \multirow{7}{*}{$\begin{array}{l}\text { Reflexão } \\
36 \\
(65,4 \%)\end{array}$} & $\begin{array}{l}8 \\
15,7 \%\end{array}$ \\
\hline & $\begin{array}{l}1 \\
3,03 \%\end{array}$ & $\begin{array}{l}\text { Intertextualizar (produção), levando em conta outros } \\
\text { textos e discursos sobre os mesmos temas, para com eles } \\
\text { concordar, discordar, dialogar }\end{array}$ & 0 & & $\begin{array}{l}1 \\
2 * \%\end{array}$ \\
\hline & $\begin{array}{l}1 \\
3,03 \%\end{array}$ & $\begin{array}{l}\text { Elaborar apreciações relativas a valores éticos e/ou } \\
\text { políticos }\end{array}$ & $\begin{array}{l}4 \\
22,2 \%\end{array}$ & & $\begin{array}{l}5 \\
9,8 \%\end{array}$ \\
\hline & 0 & $\begin{array}{l}\text { Comunicar, adequando o texto à situação de produção, } \\
\text { a seus interlocutores-leitores, a seu suporte e veículo, de } \\
\text { maneira a atingir suas finalidades }\end{array}$ & $\begin{array}{l}6 \\
33,3 \%\end{array}$ & & $\begin{array}{l}6 \\
11,8 \%\end{array}$ \\
\hline & $\begin{array}{l}4 \\
12,1 \%\end{array}$ & Recuperar contexto do texto & $\begin{array}{l}11 \\
61,1 \%\end{array}$ & & $\begin{array}{l}15 \\
29,4 \%\end{array}$ \\
\hline & $\begin{array}{l}1 \\
3,03 \% \\
\end{array}$ & Elaborar apreciações estéticas e/ou afetivas & $\begin{array}{l}2 \\
11,1 \% \\
\end{array}$ & & $\begin{array}{l}3 \\
5,9 \% \\
\end{array}$ \\
\hline & $\begin{array}{l}25 \\
75,5 \% \\
\end{array}$ & Expressar suas opiniões pessoais & $\begin{array}{l}9 \\
50 \% \\
\end{array}$ & & $\begin{array}{l}34 \\
66,7 \% \\
\end{array}$ \\
\hline \multirow{4}{*}{$\begin{array}{l}\text { Identificação } \\
23 \\
(38,3 \%)\end{array}$} & 0 & Perceber relações de interdiscursividade; & 0 & \multirow{4}{*}{$\begin{array}{l}\text { Identificação } \\
18 \\
(32,7 \%)\end{array}$} & 0 \\
\hline & $\begin{array}{l}1 \\
3,03 \%\end{array}$ & Perceber relações de intertextualidade; & $\begin{array}{l}2 \\
11,1 \%\end{array}$ & & $\begin{array}{l}3 \\
5,9 \%\end{array}$ \\
\hline & $\begin{array}{l}22 \\
66,6 \% \\
\end{array}$ & Relacionar texto e contexto pessoal; & $\begin{array}{l}3 \\
16,6 \% \\
\end{array}$ & & $\begin{array}{l}25 \\
49 \% \\
\end{array}$ \\
\hline & 0 & $\begin{array}{l}\text { Definir finalidades e metas da atividade de leitura e/ou } \\
\text { escrita. }\end{array}$ & $\begin{array}{l}13 \\
72,2 \%\end{array}$ & & $\begin{array}{l}13 \\
25,5 \% \\
\end{array}$ \\
\hline $\begin{array}{l}60 \\
(100 \%)\end{array}$ & $\begin{array}{l}60 \mathrm{em} \\
33 \text { atividades } \\
100 \%\end{array}$ & & $\begin{array}{l}55 \mathrm{em} \\
18 \text { atividades } \\
(100 \%)\end{array}$ & $\begin{array}{l}55 \\
(100 \%)\end{array}$ & $\begin{array}{l}115 \mathrm{em} \\
51 \text { atividades } \\
(100 \%)\end{array}$ \\
\hline
\end{tabular}

Fonte: Autoras. 
Na seção de compreensão escrita, os tipos de raciocínios e de práticas voltados ao contexto do aluno ("expressar opiniões pessoais") somados aos aspectos ideológicos de "visões de mundo" ("Na sua opinião, quais são os benefícios de estudar fora do país?", "Discuta com seu colega. Como as pessoas devem se comportar no trânsito?", "Qual a sua opinião sobre o uso de computadores em aula?" "), "identidade" ("Você respeita a cultura de outros povos?") e "valores éticos" ("Você trata as outras pessoas da mesma forma como gostaria de ser tratado?”6) restringem o conceito de LC mais para as representações do aluno e menos para a identificação de representações no texto lido. Esse tipo de abordagem pode acabar limitando as possibilidades de ajudar os estudantes a reconhecerem como os textos representam realidades, a debaterem as ideologias que moldam essas representações e rejeitarem e/ou reconstruírem esses textos. Uma pedagogia para o LC que o aluno vá além do que lhe é pessoal, familiar, e consiga experienciar o novo e reconhecer, respeitar e/ ou problematizar pontos de vista alternativos.

Dentre as atividades de produção escrita, por sua vez, os enunciados levam o aluno a considerar visões de mundo em outros textos/contextos, ao orientálos a "definirem finalidades e metas da atividade de escrita" (72,2\% - 13 de 18 atividades) a partir de contextos e papéis sociais que não são uma escolha pessoal ("Imagine que você é o escritor de uma coluna de aconselhamento no jornal da escola. Pense nas questões debatidas na seção Momento da Conversa e escreva um texto curto aconselhando as pessoas as como superar aquele problema." $\left.{ }^{\prime}\right)$ e por meio de raciocínios e de práticas de associação entre texto e contexto (61,1\% - 11 de 18 atividades) ("Agora imagine que você está no acampamento de verão apresentado acima e você tem muitas novidades para contar para sua família. Hoje é Quinta-feira. Escreva uma carta para eles..., "Leia a introdução de um debate online e responda às questões relacionadas a ele. Quem é Lawrence Summers? Por que a opinião dele importa?”8). Essa perspectiva reflete a orientação do Guia de livros didáticos sobre a necessidade de "expandir as atividades de modo a não só solicitar opinião do aluno, mas também oferecer apoio para o aprofundamento da discussão do tema tratado" (BRASIL, 2013, p. 43). Mesmo assim, dentre as atividades de produção escrita, também há bastante ênfase (50\% - 9 ocorrências em 18 atividades) em raciocínios e práticas de "expressar opiniões pessoais" ("Observe os objetos abaixo. Na sua opinião, são tecnologias modernas ou antigas?”').

Notamos, portanto, que, embora haja uma soma apreciável de atividades de LC $(38,6 \%)$ no livro analisado, os tipos de raciocínios e de práticas que predominam são quase sempre os mesmos e ficam essencialmente restritos à opinião dos estudantes. Porém, conforme delineado na literatura prévia, o ciclo do LC é mais abrangente, é a capacidade de reconhecer quais e como estruturas linguísticas de diferentes textos são determinadas (e determinam) por instituições e formações ideológicas, problematizar as hierarquias sociais que são criadas por essas visões e, com uma atitude "receptiva à diversidade" (JORDÃO, 2016 p. 43-44), agir no sentido de perpetuá-las (se são visões inclusivas, por exemplo), ou desafiá-las (se são visões opressoras), aplicando o conhecimento adquirido a novos textos/ 
contextos. Nesse ponto, o LC chega ao nível mais elevado da intervenção no contexto do aluno, para além da sala de aula, promovendo sua participação agentiva, cidadã, nos contextos que venham a ser relevantes para ele.

Conforme mostra a Tabela 4, identificamos uma atividade de compreensão escrita e uma de produção escrita que podem ser associadas a este nível de raciocínios e de práticas de LC, especificamente de "aplicar o conhecimento de forma inovadora", reproduzidas nas Figuras 4 e 5 a seguir.

A Figura 4 traz a atividade de compreensão escrita, parte da Unidade 3 do livro, que tem como tema o intercâmbio estudantil e a aprendizagem de línguas adicionais. $\mathrm{O}$ texto da seção apresenta dicas de viagem para estudantes de intercâmbio e a atividade 7 (Figura 4), que é a última da seção, diz o seguinte em português: "Se você tivesse que dar dicas de segurança sobre seu país para um estrangeiro, o que você diria? Que informações no texto você mudaria? Você incluiria alguma outra informação? Discuta com um colega e, depois, tome notas”.

Figura 4: Exemplo de atividade de compreensão escrita que demanda raciocínios e práticas de LC

7 If you had to give safety tips about your country to a foreigner, what would you say? What information in the text would you change? Would you add any other information? Discuss with a classmate and, after that, write down some notes. Pessoal. Pergunte aos alunos se eles acham que todas as recomendações do texto devem ser seguidas e $\frac{\text { quais medidas eles consideram mais importantes. Incentive-os a dizer, também, quais dicas seriam }}{\text { quam }}$ desnecessárias na opinião deles (se houver).

Veja, nas Orientações para o professor, comentários sobre esta atividade.

Fonte: Killner; Amancio (2012, p. 35).

Em termos de nível da ideologia, a atividade explora saberes relacionados a categorias como "pontos de vista" ("Se você tivesse que que dar dicas...") e "identidade" ("dicas sobre o seu país para um estrangeiro"). Contudo, para resolver a atividade, o estudante precisa ainda desempenhar raciocínios e práticas relacionados ao momento de Identificação, como "relacionar o texto ao contexto pessoal", em que o estudante, com base no texto, compara as dicas de segurança sobre outro país com o seu próprio ("dicas sobre o seu país para um estrangeiro"... "Que informações no texto você mudaria?”). Além disso, raciocínios e práticas de Reflexão também precisam ser mobilizados, como "elaborar apreciações relativas a valores éticos e/ou políticos", ou seja, conferir as dicas do texto com as quais o estudante concorda ou discorda, quais delas poderia usar para dar dicas para um estrangeiro no Brasil, quais delas mudaria, para, na sequência, "expressar sua opinião". O enunciado da questão orienta que o estudante "Tome notas" sobre possíveis dicas, a partir do raciocínio/prática de "intertextualizar, levando em conta outros textos e discursos sobre os mesmos temas, para com eles concordar, discordar, dialogar”. Nas "Orientações para o professor”, há uma ênfase para que o estudante escreva dicas de viagem para seu 
país, que sejam semelhantes, diferentes, adaptadas, mas específicas ao contexto do seu país (KILLNER; AMANCIO, 2012). Assim, a atividade demanda que o estudante "aplique o conhecimento de forma inovadora", que é um dos raciocínios e práticas do momento de Ação do LC. Não há uma especificação sobre a publicação das dicas escritas pelos estudantes, considerando um "engajamento social", o qual poderia ser orientado pelo professor; contudo, vemos a proposta de reescrever essas dicas como uma tentativa de conduzir o estudante e se ver em um papel ativo sobre as situações. Essa atividade aparece ao final da seção. Kalantzis et al. (2016, p. 75) preveem que esse processo aconteça a partir de conhecimento que o estudante já aprendeu, sendo uma "intervenção inovadora e criativa no mundo, distintamente, expressando suas próprias vozes ou transferindo esse conhecimento para um contexto diferente".

O exemplo da Figura 5 está entre as atividades de produção escrita e também envolve o momento de Ação, além de outros raciocínios e práticas. O enunciado da atividade introduz a produção escrita da seção e os itens da parte "Before production" (Antes da produção) orientam a escrita em si. Consideramos essas duas partes como uma única tarefa pois ambas precisam ser consideradas para a execução da atividade. A fim de contextualizar, destacamos que a seção de produção escrita dessa unidade introduz, inicialmente, um debate online sobre a aprendizagem de línguas estrangeiras nos Estados Unidos e, junto com esse texto, algumas questões para discussão. O enunciado (Figura 5) instrui o estudante a "expressar sua opinião" sobre assunto a partir da escrita de um artigo de opinião: "É hora de dar sua opinião! Imagine que você tivesse a oportunidade de postar um artigo no The New York Times dando sua opinião sobre esse assunto. O que você escreveria?”.

Figura 5: Exemplo de atividade de produção escrita que demanda raciocínios e práticas de LC It's time to give your opinion! Suppose you had the opportunity to post an article
for The New york Times giving your opinion on this issue. What would you write?

\section{Before production}

Veja, nas orientaçóes para o professor, comentárias sobre esta subseção.

- Use strong arguments to support your position.

- If necessary, search for data in newspapers and/or the internet to support your point in your notebook. Presenteso de resposta afirmativa, peca aos alunos que digam quais informaçoes

After production faz ver umlado da questão que eu náo conseguia enxergar sozinho.

Pair up with a classmate, read his/her opinion article and answer the questions

a) Do you agree with your classmate's arguments? Why? pessoal

Fonte: Killner; Amancio (2012, p. 42).

Além de categorias como "pontos de vista" ("É hora de dar sua opinião!"), verificamos o raciocínio/prática de "relacionar o contexto do texto ao contexto pessoal", em que o estudante compara aquele contexto (a importância do aprendizado de línguas em outro país) diferente do seu, e é convidado a reconhecer a sua visão. O estudante precisa, então, "definir as finalidades e metas da atividade de escrita", ou seja, conscientizar-se sobre o que precisa fazer na atividade e se precisa buscar informações extras para seus argumentos, como sugerido nas indicações no segun- 
do e no terceiro itens da parte "Before production": segundo item - "use argumentos fortes para sustentar sua posição", terceiro item - "se necessário, pesquise por dados em jornais, e/ou internet para sustentar suas ideias em seu caderno".

Além disso, raciocínios e práticas de Reflexão também são necessários para resolver o exemplo da Figura 5, como "recuperar o contexto do texto", refletindo sobre onde esse tipo de texto é publicado, quem costuma produzir, qual é a finalidade. A primeira indicação da parte "Before production" é refletir sobre a concordância ou não quanto à posição do produtor do texto da atividade anterior: "decida se você concorda ou não com a posição de Lawrence Summer [o autor do texto]". Assim, o estudante é convidado a "elaborar apreciações relativas a valores éticos e/ou políticos", concordando, discordando, criticando as visões propostas no texto, além de "problematizar significados/representações expressos nos textos ou situações", ou seja, verificar se aquela posição é igual em todo o lugar, como escrever diferente, para a partir disso escrever seu artigo.

Uma orientação do livro para o professor sobre essa atividade sugere ainda "[d]iga-lhes que esses textos costumam ser publicados em jornais, revistas, websites da internet e refletem a opinião do autor sobre um assunto específico" (KILLNER; AMANCIO, 2012, p. 51). Sendo assim, poderíamos dizer que a atividade demanda que o estudante "comunique, adequando o texto à situação de produção, a seus interlocutores-leitores, a seu suporte e veículo, de maneira a atingir suas finalidades".

A produção escrita do estudante, a partir disso, pode ser entendida como uma "aplicação do conhecimento de forma inovadora" que diz respeito a fazer diferente do texto estudado (do que o texto publicado), expressando suas próprias vozes e propondo seu conhecimento (de um brasileiro, que tem pelo menos uma disciplina de língua estrangeira na escola e que é estimulado a aprender diferentes línguas - considerando o tópico da seção) para um contexto diferente (do Brasil para o de outro país - o jornal The New York Times).

Essa atividade (Figura 5) seria a atividade orientadora da produção escrita da seção que é realizada com foco em uma breve atividade de compreensão escrita, como destacamos. Na sequência, ainda aparecem atividades de "After production", de "pós-produção", as quais, considerando as seções de produção escrita, geralmente sugerem discussões, reflexões sobre os tópicos das seções. Da mesma forma, as seções de compreensão trazem atividades "pós-leitura", cujo objetivo geralmente é propor discussões sobre algum aspecto do texto com relação ao contexto, ou seja, reflexões que poderiam abordar elementos de natureza crítica (WALLACE, 1992; MOTTA-ROTH, 2008b).

Na sequência, discutimos em que medida as imagens são exploradas criticamente dentre as atividades de LC, para promoção do LCV.

\section{Atividades de LCV}

Em primeiro lugar, é importante mencionar que a presença de imagens nas seções analisadas é relativamente baixa. Em termos de páginas, apenas 13 de 33 
incluem imagens, que em geral são pouco salientes na página (Figura 6) se comparadas ao volume de linguagem verbal. A maior parte das imagens estão associadas a atividades em particular e não aos textos. Apenas 3 de 12 textos presentes nas unidades de compreensão escrita incluem imagem (destacados dentro das bordas pontilhadas na Figura 6). Dentre 51 atividades de LC, seis apresentam imagens, e cinco as exploram.

Figura 6: Presença de imagens nos textos das seções de compreensão escrita Fonte: Killner; Amancio (2012, p. 47, 58, 99).

Como explicam Salbego, Heberle e Balen (2015), para estudantes iniciantes em uma língua adicional, a exploração dos significados de imagens pode ser mui-
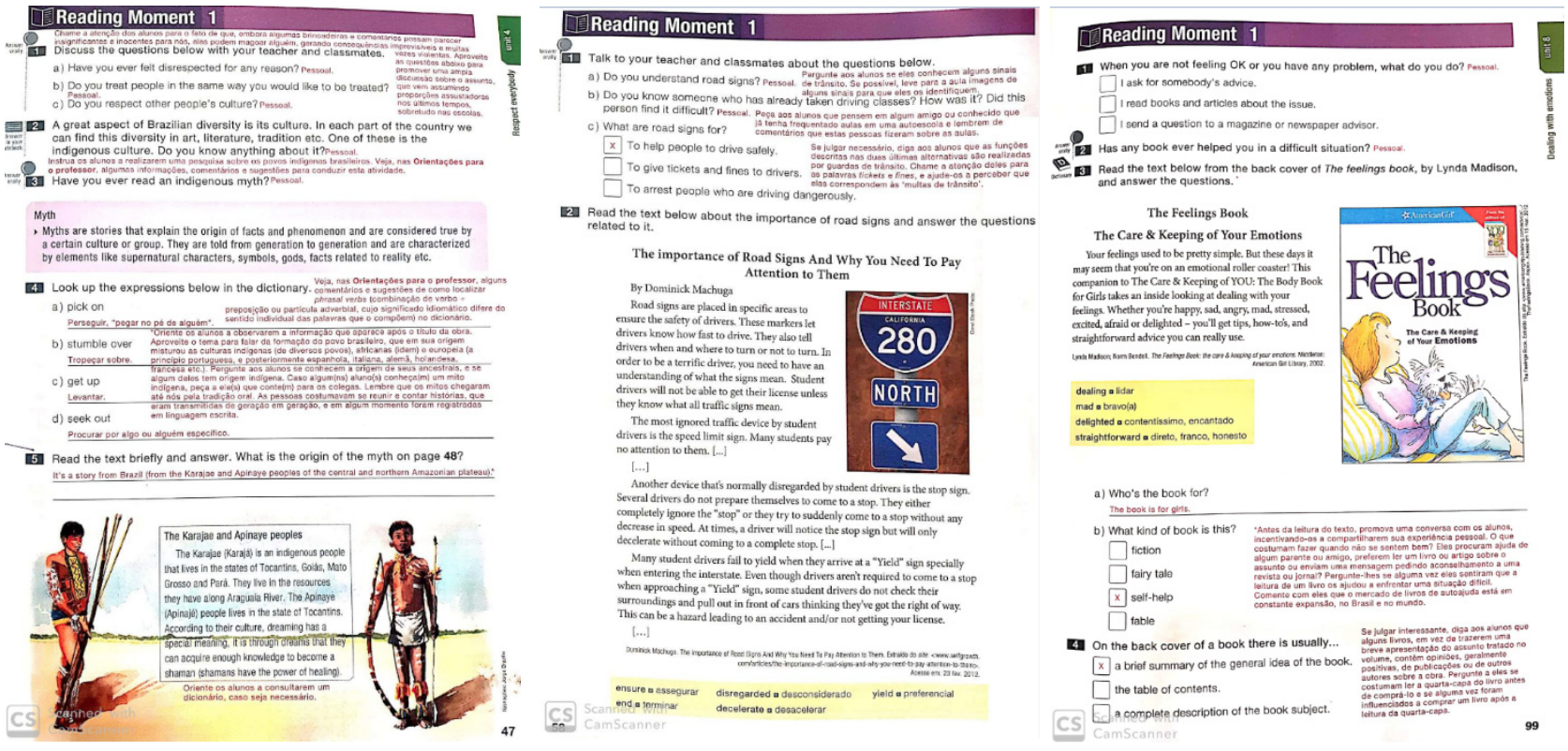

to importante por funcionarem como andaimes para acessar a linguagem verbal. O "léxico" visual (pessoas, coisas, espaços e ações representadas) de fotografias ou de tiras em quadrinho pode ser mais familiar aos alunos do que o léxico verbal da língua adicional. Entendemos que essa familiaridade também é favorável para acessar os níveis de raciocínio e práticas mais complexos associados ao LCV.

Os aspectos da ideologia explorados nas cinco atividades identificadas são "pontos de vista" (em 4 atividades), mas no caso das atividades de compreensão, esses saberes são mais variados, como "valores éticos" (2 atividades), "identidade" (2 atividades). Com relação aos raciocínios e práticas, há um foco em "recuperar o contexto do texto" (3 atividades), "expressar opiniões pessoais" (3 atividades) e a "relacionar texto e contexto pessoal (2 atividades)".

A Figura 7 mostra exemplos de atividades que exploram as imagens sob um viés crítico. Na atividade de compreensão escrita 3 (parte da Unidade 8), o enunciado principal orienta o estudante a ler o texto (quarta capa de um livro) e responder as perguntas indicadas pelas letras a e b, sobre público-alvo (a) do livro mencionado no texto e o tipo de livro do qual trata (b). A orientação para o professor, em rosa, também sugere uma atividade de conversa antes da leitura, sobre 
o que os estudantes fazem quando tem algum problema, se procuram ajuda, de quem ou de que forma, e se conhecem livros de autoajuda. Em termos de LCV, a atividade sobre o público-alvo do texto aciona um raciocínio de reflexão e a prática de "recuperar o contexto do texto". Apesar de o texto mencionar que o livro é "para meninas" (“for Girls"), a imagem possibilita uma identificação mais rápida dessa resposta e mais precisa em termos de faixa etária, por exemplo, apesar de ser uma ilustração com traços menos detalhados do que uma fotografia. A partir dessa questão e com uma problematização conduzida pelo professor, a leitura/ análise crítica da imagem possibilita que os estudantes reflitam sobre o componente ideológico "identidade" do participante representado visualmente: quem é (gênero, etnia, faixa etária, classe socioeconômica)?, parece que tem algum problema?, qual?, esse tipo de problema também afeta as meninas da turma?, só as meninas têm problemas com sentimentos?, as meninas têm mais problemas sentimentais do que os meninos?, problemas de meninas e meninos são diferentes? como?, como seria o título de um livro de autoajuda para meninos?, qual a relação dessa representação visual do público alvo com o contexto de produção do livro?, e assim por diante.

Figura 7: Exemplos de atividades de compreensão escrita (à esquerda) e de produção escrita (à direita) que demandam saberes de LCV
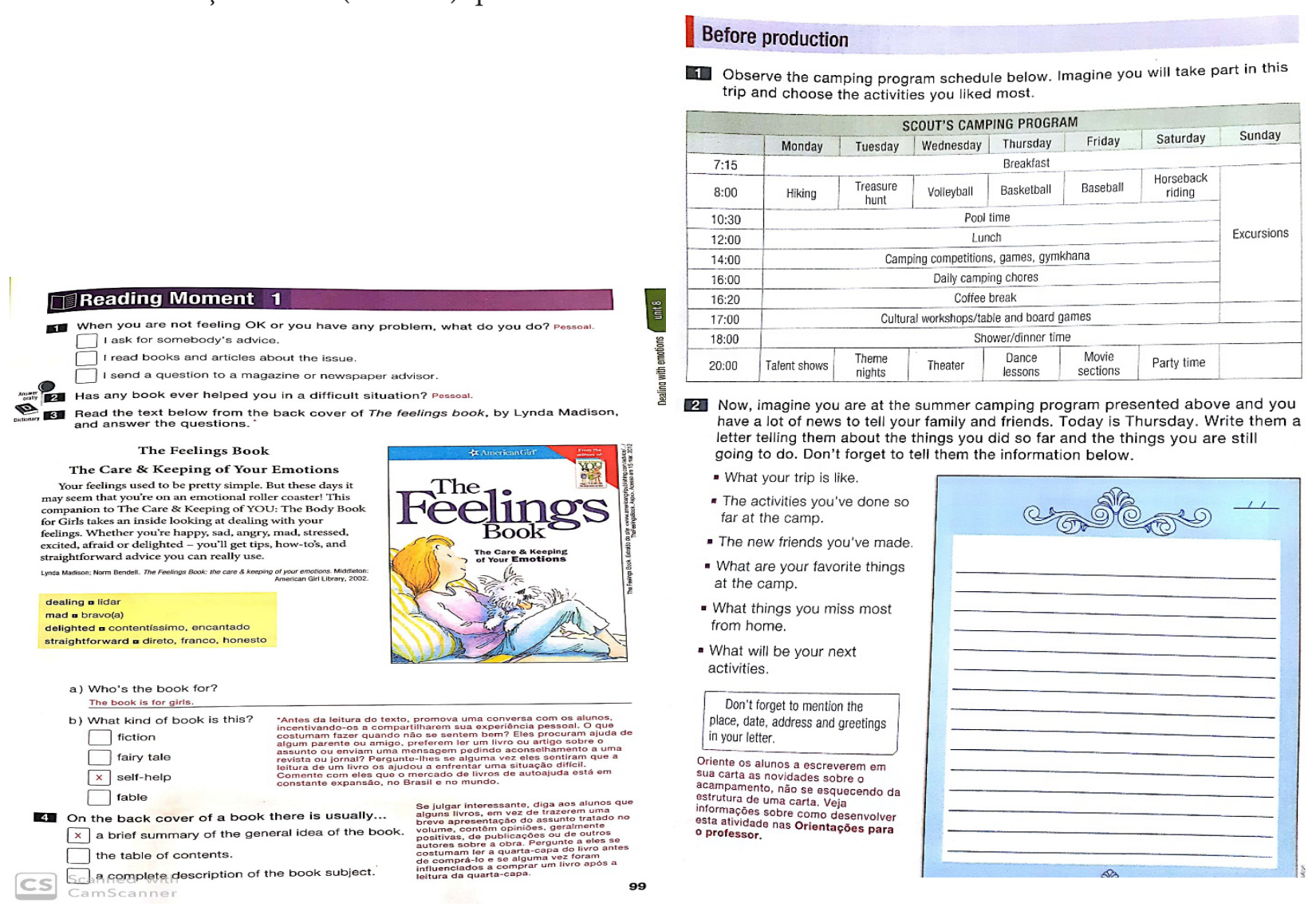

Fonte: Killner, Amancio (2012, p. 99 e 16, respectivamente). 
A atividade de produção escrita (Figura 7, à direita) faz parte da Unidade 1 e requer que o estudante escolha as atividades que mais gosta no programa de acampamento apresentado (quadro), enquanto que a atividade 2, que orienta a escrita, sugere que o estudante use o programa como base para escrever uma carta para sua família, imaginando que estivesse participando de um acampamento. A atividade 2 diz "Agora, imagine que você está no programa de acampamento apresentado acima e tem muitas novidades para contar a sua família e amigos. Hoje é quinta. Escreva uma carta contando para eles as coisas que você já fez e aquelas que vai fazer. Não esqueça de contar sobre as informações abaixo". Na sequência, são listados itens que o estudante deve incluir na carta: impressões sobre a viagem, atividades que já realizou, novas amizades, atividades favoritas, coisas de casa das quais sente falta, atividades que ainda fará.

Em termos de ideologia, o estudante expõe seu "ponto de vista" considerando as atividades do programa de que mais gosta, de quais gostaria de participar, de quais nunca participou em sua vida. Em termos de saberes sobre letramento visual, o programa tem um formato de quadro, com dias da semana, horários e atividades cuja finalidade e organização o estudante precisa reconhecer, acionando as metafunções representacional - o que está representado, e composicional - como está organizado (KRESS; VAN LEEUWEN, 2006), que são categorias do nível da semântica e pragmática. Além disso, o estudante precisa reconhecer o programa como um gênero discursivo, provavelmente produzido por organizadores de um acampamento para participantes - provavelmente estudantes da mesma idade (registro); em outras palavras, o estudante "recupera o contexto do texto", do quadro e também da sua carta, se colocando como produtor de uma carta para sua família, considerando as finalidades sugeridas na orientação da atividade 2 .

Vemos que os raciocínios e práticas explorados nas atividades especificamente sobre imagens estão dentre os mais frequentes já identificados na seção anterior: "expressar opiniões pessoais", "recuperar o contexto do texto" e "relacionar texto e contexto pessoal". Conforme já apontado, essa ênfase pode sugerir uma redução do conceito de $\mathrm{LC}(\mathrm{V})$ a representações dos alunos e à identificação de autoria e público-alvo, sem problematizar as representações presentes nas imagens. Com isso, o potencial de uso de ferramentas como a gramática visual também fica limitado.

\section{Considerações Finais}

Nosso objetivo principal neste estudo foi investigar como saberes de LC e LCV são abordados no contexto pedagógico de ensino de inglês, por meio da análise de um livro didático. Tomamos como base o conceito de LC como um conjunto de saberes para participação bem-sucedida e consciente em um repertório variado de gêneros discursivos, que incluem o reconhecimento de padrões linguísticos e os interesses e relações de poder que os perpassam e o uso de ferramentas para promover transformação social com vistas a romper representações de desigualdades, preconceitos, discriminações, exclusão social, injustiça social. 
Avaliamos positivamente a frequência de atividades para o desenvolvimento de saberes de LC, principalmente em seções direcionadas à compreensão escrita em inglês. Todavia, a natureza dessas atividades é pouco variada, considerando os tipos de raciocínios e de práticas que exploram, já que se limitam predominantemente a "expressar opinião pessoal" e "relacionar texto ao contexto pessoal", e, em menor escala, a "relacionar texto e contexto", por meio da identificação de autoria, local de publicação e/ou público-alvo. Além disso, percebemos que o elemento crítico se estende de maneira tímida para saberes relacionados ao caráter multimodal da linguagem, pois é previsto principalmente em aulas de leitura enfocando saberes relacionados a recursos semióticos verbais. Esse resultado aponta para a necessidade de mais estudos que possam contribuir para uma conscientização sobre o papel das imagens nos textos e representações de posições ideológicas em imagens (VAN LEEUWEN, 2008).

Embora os raciocínios e práticas predominantes nas seções analisadas sejam fundamentais, eles revelam um ciclo incompleto de LC, pois além da Identificação (de pistas do contexto no texto, por exemplo) e da Reflexão (por meio da manifestação de opiniões pessoais), há uma série de atividades a serem desenvolvidas para cumprir o ciclo e culminar no estágio final de Ação: debater respeitosamente pontos de vista conflitantes com o seu, problematizar visões de mundo naturalizadas expressas nos textos (multimodais), considerando outras representações/visões de mundo possíveis, aplicar o conhecimento de forma inovadora, a novos contextos, engajar em ações sociais (níveis mais altos, em tom mais claro na Figura 2). Esses tipos de atividades ajudarão a "produzir estudantes que podem contribuir para uma maior equidade, capazes de respeitar o diferente e viver em harmonia com os outros, e que podem ter um papel ativo na proteção do meio ambiente" (JANKS, 2013, p. 227). Nesse sentido, gostaríamos de destacar o papel do professor em complementar o material didático e conduzir as aulas para discussões que englobem essas atividades.

Para finalizar, destacamos que nossa proposta de sistematização de LC pode ser entendida como uma tentativa de contribuir para o ensino de inglês em uma perspectiva multimodal e crítica. Contudo, entendemos que o conceito é denso, recente e ressaltamos a necessidade de mais estudos e ações sobre o tema voltadas para o ensino.

\section{Notes}

1. O ano inicial da pesquisa foi 2016, realizada na Universidade Federal de Santa Maria, por isso foi selecionado esse triênio do PNLD e o contexto local de Santa Maria. Ficamos restritos aos anos finais do ensino fundamental em vista da inexistência de distribuição de livros de inglês do PNLD para os anos iniciais (BRASIL, 2016). Além disso, em outra fase da pesquisa, analisamos também os livros indicados ao contexto de ensino médio, mas por limitações de espaço, não reportaremos os resultados dessa fase neste trabalho.

2. Percentuais arredondados.

3. A esse propósito, Cervetti, Pardales e Damico (2001) trazem exemplos de atividades de letramento crítico desenvolvidas com crianças de seis anos de idade, que são levadas a identificar e questionar representações de mãe e maternidade em panfletos de Dia das Mães. 
4. No original, respectivamente: "In your opinion, which are the benefits of studying abroad?", "Discuss with your classmates. How should a person behave on the road?", "What's your opinion about the use of computers during classes?"

5. No original: "Do you respect other people's culture?"

6. No original: "Do you treat people in the same way you would like to be treated?"

7. No original: "Imagine you are the writer of an advice column at the school newspaper. Think about the issues you've discussed in the section Conversation Moment and write down a short text advising people in how to overcome that problem."

8. No original, respectivamente: "Now, imagine you are at the summer camping program presented above and you have a lot of news to tell your family and friends. Today is Thursday. Write them a letter..."; "Read the introduction of an online debate and answer the questions related to it. Who is Lawrence Summers? Why is his opinion relevant?"

9. No original: "Observe the objects below. In your opinion, are they modern or old technologies?"

\section{Referências}

ASKEHAVE, I.; SWALES, J. M. Genre identification and communicative purpose: a problem and a possible solution. Applied Linguistics, v. 22, n. 2, p. 195-212, 2001.

BARTON, E. Linguistic discourse analysis: how the language in text works. In: BAZERMAN, C.; PRIOR, P. (Eds.). What writing does and how it does it: an introduction to analyzing texts and textual practices. New Jersey: Lawrence Erlbaum Associates, 2004. p. 57-82.

BHATIA, V. K. Worlds of Written Discourse: a genre-based view. London: Continuum, 2004.

BHATIA, V. K. Towards critical genre analysis. In: BHATIA, V. K.; FLOWERDEW, J.; JONES, R. (Eds.). Advances in discourse studies. London: Routledge, 2008. p. 166-177.

BHATIA, V. K. Critical genre analysis: theoretical preliminaries. Hermes - Journal of Language and Communication in Business, n. 54, p. 9-20, 2015.

BRASIL. MEC/SEC. Parâmetros curriculares nacionais: terceiro e quarto ciclos do ensino fundamental - Língua estrangeira. Brasília: MEC/SEF, 1998. Disponível em: <http://portal.mec.gov.br/seb/arquivos/pdf/pcn_estrangeira.pdf $>$. Acesso em: 24 mai. 2016.

BRASIL. MEC/SEC. Orientações curriculares para o ensino médio - Linguagens, Códigos e suas Tecnologias. v. 1. Brasília: MEC/SEC, 2006. Disponível em: http:// portal.mec.gov.br/seb/arquivos/pdf/book_volume_01_internet.pdf. Acesso em: 10 mai. 2012.

BRASIL. Edital de convocação para o processo de inscrição e avaliação de coleções didáticas para o Programa Nacional do Livro Didático PNLD 2014 - Ensino Fundamental. Brasília: MEC/SEB, 2011.

BRASIL. MEC/SEF. Guia de Livros Didáticos PNLD 2014: Língua Estrangeira Moderna - Ensino Fundamental Anos Finais. Brạsíliạ: FAE, 2013.

BRASIL. MEC/SEF. SIMAD/Sistema do Material Didático: Distribuição. Fundo Nacional de Desenvolvimento da Educação. Brasília: MEC/SEF, 2014. Disponível em: <www.fnde.gov.br/distribuicaosimadnet/pesquisar>. Acesso em: 14 abril 2014.

BRASIL. MEC/SEF. Sobre o Livro Didático. Fundo Nacional de Desenvolvimento da Educação. Brasília: FNDE, 2016. Disponível em: < http://www.fnde.gov.br/ 
programas/livro-didatico >. Acesso em: 16 abril 2016.

CAZDEN, C.; COPE, B.; FAIRCLOUGH, N.; GEE, J.; et al. A pedagogy of multiliteracies: Designing social futures. Harvard Educational Review, v. 66, n. 1, p. 60-92, 1996.

CERVETTI, G.; PARDALES, M. J.; DAMICO, J. S. A tale of differences: comparing the traditions, perspectives and educational goals of critical reading and critical literacy. Reading Online, v. 4, n. 9, 2001. Disponível em: <http://www. readingonline.org/articles/cervetti/ > Acesso em: 13 set. 2014.

COPE, B.; KALANTZIS, M. Introduction. Multiliteracies: the beginning of an idea. In: COPE, B.; KALANTZIS, M. (Eds.). Multiliteracies: literacy learning and the design of social futures. London: Routledge, 2000. p. 3-8.

COPE, B.; KALANTZIS, M. Multiliteracies: new literacies, new learning. Pedagogies: An International Journal. v. 4, n. 3, p. 164-195, 2009.

FAIRCLOUGH, N. Introduction. In: Critical language awareness. New York: Longman, 1992a. p. 1-30

FAIRCLOUGH, N. Discourse and social change. Cambridge: Polity Press. 1992b.

FAIRCLOUGH, N. Language and Power. London: Longman. [1989]2001.

FAIRCLOUGH, N. Analysing discourse: textual analysis for social research. New York: Routledge, 2003.

FLOREK, C. S. Uma análise crítica de gênero de resumos acadêmicos gráficos. 2015. 238p. Dissertação (Mestrado em Letras). Universidade Federal de Santa Maria, Santa Maria, 2015.

FREIRE, P. A importância do ato de ler: em três artigos que se completam. $23^{\mathrm{a}}$ ed. São Paulo: Autores Associados: Cortez, 1989.

FREIRE, P. Pedagogia do oprimido. 50 ed. São Paulo: Editora Paz e Terra LTDA, 2011.

HALLIDAY, M. A. K.; HASAN, R. Language, context, and text: aspects of language in a social-semiotic perspective. Oxford: Oxford University Press, 1989.

HALLIDAY, M. A. K. An introduction to functional grammar. 1. ed. London: Arnold, 1994.

HALLIDAY, M. A. K.; MATHIESSEN, C. An introduction to functional grammar. 4. ed. London: Arnold, 2014.

JANKS, H. Critical literacy in teaching and research. Education Inquiry, v. 4, n. 2, p. $225-242,2013$.

JORDÃO, C. M. No Tabuleiro da Professora Tem.... Letramento Crítico? In: Dánie Marcelo de Jesus; Divanize Carbonieri. (Org.). Práticas de Multiletramentos e Letramento Crítico: outros sentidos para a sala de aula de línguas. 1. ed. Campinas: Pontes Editores Ltda, 2016, p. 41-56.

KALANTZIS, M.; COPE, B. Literacies. New York: Cambridge University Press, 2012.

KALANTZIS, M.; COPE, B.; CHAN, E.; DALLEY-TRIM, L. Literacies. 2. ed. Port Melbourne, VIC: Cambridge University Press, 2016.

KILLNER, M.; AMANCIO, R. G. Vontade de saber inglês: $9^{\circ}$ ano. 1. ed. São Paulo: Editora FTD, 2012.

KRESS, G. Visual and verbal modes of representation in electronically mediated communication: the potential of new forms of text. In: SNYDER, I. Page to screen: taking literacy into the electronic era. London: Routledge, 1997. p. 53-79. 
KRESS, G.; JEWITT, C. Introduction. In: JEWITT, C.; KRESS, G. (Eds.). Multimodal literacy. New York: Peter Lang Publishing, 2003. p. 1-18.

KRESS, G.; VAN LEEUWEN. T. Reading images: the grammar of visual design. 1. ed. London: Routledge, 1996.

KRESS, G.; VAN LEEUWEN. T. Reading images: the grammar of visual design. 2. ed. London: Routledge, 2006.

KUMMER, D. A. Letramento multimodal crítico: sob a perspectiva de livros didáticos e de professores de inglês e de biologia. 2015. 149 f. Dissertação (Mestrado em Letras). Universidade Federal de Santa Maria, Santa Maria. 2015.

KUMMER, D. A. Letramento multimodal crítico no ensino de inglês na escola: o papel dos livros didáticos e dos professores. 2019. 227 f. Tese (Doutorado em Letras). ). Universidade Federal de Santa Maria, Santa Maria. 2019.

LANKSHEAR, C., KNOBEL, M. New literacies. 3. ed. New York/Berkshire: McGraw Hill/Open University, 2011.

LUKE, A. Defining critical literacy. In: PANDYA, J. Z.; ÁVILA, J. (Eds.). Moving critical literacies forward: a new look at praxis across contexts. New York: Routledge, 2014. p. 19-31.

MACHIN, D. What is multimodal critical discourse studies. Critical Discourse Studies, v. 10, n.4, p. 347-355, 2013.

MAGALHÃES, I. Introdução: a análise de discurso crítica. D.E.L.T.A., v. 21, n. especial, p. 1-9, 2005.

MEURER, J. L. Gêneros textuais na análise crítica de Fairclough. In: MEURER, J. L.; BONINI, A.; MOTTA-ROTH, D. (Orgs.). Gêneros: teorias, métodos, debates. São Paulo: Parábola Editorial, 2005. p. 81-106.

MEURER, J. L. Integrando estudos de gêneros textuais ao contexto de cultura. In: KAWORSKY, A. M.; GAYDECZKA, B.; BRITO, K. S. (Orgs.). Gêneros textuais: reflexões e ensino. 4. ed. São Paulo: Parábola Editorial, 2011. p. 175-196.

MOTTA-ROTH, D. Questões de metodologia em análise de gênero. In: KAWORSKY, A. M.; GAYDECZKA, B.; BRITO, K. S. (Orgs.). Gêneros textuais: reflexões e ensino. 2. ed. Revista a Aumentada. Rio de Janeiro: Lucerna, 2006. p. 145-163.

MOTTA-ROTH, D. Análise crítica de gêneros: contribuições para o ensino e a pesquisa de linguagem. D.E.L.T.A, v. 24, n. 2, p. 341-383, 2008 a.

MOTTA-ROTH, D. Para ligar a teoria à prática. In: MOTTA-ROTH, D.; CABAÑAS, T.; HENDGES, G. R. (Orgs.). Análises de textos e de discursos: relações entre teorias e práticas. Santa Maria, RS: Editora do PPGL, 2008b. p. 243-272.

MOTTA-ROTH, D.; HEBERLE, V. M. A short cartography of genre studies in Brazil. Journal of English for Academic Purposes, v. 19, p. 22-31, 2015.

PREDEBON, N. R. C. Do entretenimento à crítica: letramento multimodal crítico no livro didático de inglês com base em gêneros dos quadrinhos. 2015. 241f. Tese (Doutorado em Letras). Universidade Federal de Santa Maria: Santa Maria. 2015.

ROJO, R. Letramento e capacidades de leitura para a cidadania. São Paulo: SEE: CENP, 2004.

ROJO, R. Letramentos múltiplos, escola e inclusão social. São Paulo: Parábola Editorial, 2009.

SALBEGO; N.; HEBERLE, V. M.; BALEN, M. G. S. da S. A visual analysis of English textbooks: multimodal scaffolded learning. Calidoscópio, v. 13, n. 1, p. 5-13, 2015. 
TÍLIO, R. Atividades de leitura em livros didáticos de inglês: PCN, letramento crítico e o panorama atual. RBLA, v. 12, n. 4, p. 997-1024, 2012.

TRIVISIOL, V.S. O conceito de (multi)letramentos subjacente às atividades pedagógicas produzidas para uma unidade didática em um programa de formação continuada na escola pública. 2017, 139f. Dissertação (Mestrado em Letras). Universidade Federal de Santa Maria: Santa Maria, 2017.

UNSWORTH, L. Changing dimensions in school literacies. In: UNSWORTH, L. Teaching multiliteracies across the curriculum. Berkshire, QL: Open University Press, 2001. p. 7-20.

VAN LEEUWEN, T. The representation of social actors. In: CALDAS-COULTHARD, C. R.; COULTHARD, M. (Eds.). Texts and practices: readings in critical discourse analysis. London: Routledge, 1996. p. 32-70.

VAN LEEUWEN, T. The visual representation of social actors. In: . Discourse and practice: new tools for critical discourse analysis. New York: Oxford University Press, 2008. p. 136-148.

VAN LEEUWEN, T. Critical analysis of multimodal discourse. In: CHAPELLE, C. A. (Ed.). Encyclopedia of applied linguistics. Oxford/London: Wiley-Blackwell, 2013. p. 4002-4006.

WALLACE, C. Reading. Oxford: Oxford University Press, 1992.

Recebido em: 31/07/2019

Aceito em: 13/11/2019 